\title{
A Method of Weight Update in Group Decision- Making to Accommodate the Interests of All the Decision Makers
}

\author{
Hamdani Hamdani \\ Department of Computer Science and Electronics, Faculty of Mathematics and Natural Science, \\ Universitas Gadjah Mada, Yogyakarta, Indonesia \\ Department of Computer Science, Faculty of Computer Science and Information Technology, \\ Mulawarman University, Samarinda, Indonesia \\ E-mail: hamdani@fkti.unmul.ac.id \\ Retantyo Wardoyo and Khabib Mustofa \\ Department of Computer Science and Electronics, Faculty of Mathematics and Natural Science, \\ Universitas Gadjah Mada, Yogyakarta, Indonesia \\ E-mail: rw@ugm.ac.id, khabib@ugm.ac.id
}

Received: 30 March 2017; Accepted: 15 April 2017; Published: 08 August 2017

\begin{abstract}
The weight updates are required for group decision-making which has similar parameters used by the decision maker (DM). Each DM as the stakeholder may have similar or different parameters in selecting parameters. Therefore, we have to accommodate the interests of all decision makers (DMs) to obtain alternative decisions. DM who has selected the parameters inputs the initial weight $\left(\boldsymbol{W}_{\boldsymbol{P} i}\right)$ based on the classical methods, and then recalculates to obtain the updated weights $\left(\boldsymbol{W}_{\boldsymbol{j}}\right)$ until the final weight $\left(\boldsymbol{W}_{\boldsymbol{j}}^{\boldsymbol{i}}\right)$ is obtained for the alternative of group decision-making (GDM). The initial weight uses a weighting directly or multi criteria decision-making (MCDM). This method aims to provide the fairness for all DMs who have different knowledge in determining the value of the weights and the selection parameters. In order to obtain alternative decisions, we used technique for order preference by similarity to ideal solution (TOPSIS) method to update weight. In this paper, the alternative output of the decisions is applied in two stages: the decisions of each DM and the group, where this output consists of four types of alternatives. Based on the proposed method, the result of GDM shows that the third alternative is recommended in decision-making. This method is effectively performed in decision-making which has different parameters and weights of each DM to support group decision.
\end{abstract}

Index Terms-Weight update, TOPSIS, SAW, group decision-making.

\section{INTRODUCTION}

The principle of the decision-making model is based on the process of obtaining the value of the weight, the scoring and the ranking for the preference of alternative decisions. Generally, the weighting process can affect the results in determining the alternative decisions [1]. The weighting method may be performed by the multi-criteria decision-making (MCDM) as the classical weighting method [2], e.g. TOPSIS [3], [4], analytic hierarchy process (AHP) [5]-[7], simple additive weighting (SAW) [8], the theory of fuzzy sets, and the weighted least square [2] and interval Type-2 Fuzzy TOPSIS with a new entropy weight [9]. Each value of the weight derived from the parameters is obtained individually or in the group [10]. The process of model weighting is performed objectively by the statistical calculations and subjectively by determining it based on the specific considerations [11], [12].

There are two principles of basic approaches to obtain the value of weighting criteria, namely an integrated approach between subjective and objective [8]. In the subjective approach, the value of weight can be determined independently by DM. Meanwhile, in the objective approach, the value of weight is calculated mathematically; so it may ignore the influence of interest or the subjectivity of DM in [8].

Decision makers may perform weighting for each parameter based on the degree of the interest influence or the important values of the related parameters [13]. The direct weighting gives the value of weight or percentage based on the knowledge of the case implemented. Meanwhile, the indirect weighting is generally performed using computational analysis methods, namely MCDM models to produce the value of weight [14], [15].

The problems of parameter weight in group decisionmaking is that decision maker generally have his/her own way to perform weighting stages [1]. Both direct and indirect weighting are very influential in their respective main issue of DM. Each DM considered as the 
stakeholder has different interests in decision-making. Therefore, the way to accommodate the interests of all stakeholders is needed [16]. Each DM may have different weighting techniques in determining the value of parameter weight, since they perform a different problem solving approach [3] For example, the first DM uses objective weighting method, while the second DM uses a subjective weighting method.

The results of comparisons of pairwise weight at the stage of weighting in the previous research was implemented in [17] and in [18]. AHP method is effective enough in performing the comparison of parameter pairwise; therefore, the initial stage aims to determine the results of the initial weight value based on the comparison of parameter pairwise performed by each DM in [17], and required a new method to improve the weighting method [18]. Once each DM gets the weight value that is in accordance with the parameter by AHP, then the next process is implemented in order to compare the similar parameter for each DM. This stage needs to be improved related to the weighting process of parameters so that each weighting of parameter accommodates the interests of all DMs for group decision-making.

The weighting technique is required to incorporate every similar parameter selection for each DM. If each DM has similar parameters to the other, it needs a new weighting method to accommodate every interest of DM in decision-making. This technique adds a weighting method previously to produce the updated weight, as in [19]. If DM has similar parameters to other DM, it greatly affects the value of the collaboration among DMs to make a fair decision.

The purpose of this parameter weighting update method is to express how much the influence of a parameter to other parameters that have linkages among DMs. The decision maker often uses several parameters that are confronted with problems in the specific determination. Based on the level of the influence of interests of one parameter to another parameter, the function of the results of alternative decisions have been arranged [4], [5].

The weight updates are used to obtain the combined weight from each DM using the similar parameters in decision-making [20]. If DM chooses different parameter with other DMs, these parameters do not have to change the weight and will stand alone; therefore, the normalization is required. The purpose of weight updates is to improve the parameter weighting method which generally uses a direct or indirect weighting. The new weights are used to produce a collaboration decision from all the interests of DMs.

This paper proposes a weighting process performed by each DM; subsequently we performed the weight updates for the common interest from each DM who has similar parameters. The basic principle to accommodate the interests of each DM is to meet all DMs' interests in giving the appropriate weight value based on the appropriate knowledge of each DM [21]-[23]. The methods of decisions on stakeholders' models involving several experts are used in group decision. This paper improves the result in [22] in terms of forming the relation between the stakeholders that have similar parameter in each group decision-making.

\section{RELATED WORK}

In previous papers, there are several weighting techniques that have been developed to resolve the issue of GDM. Those techniques are individual models [10], [24], adjustment method of the weights on each expert [15], and subjective and objective weights based on the interests of each DM [8], fuzzy based [25], AHP for multi-spatial problems [26], the rule of thumb (ROT) [27], three-way group decisions with decision-theoretic rough sets [28], a method for large group decision-making based on evaluation information with participators from multiple groups [29].

The weighting techniques are performed based on the opinion in decision-making that use scoring vectors (SV) to modify the initial score of the poll correspondent, but not based on the similar parameters of each DM [10]. Meanwhile, the similar weights are performed from the experts by determining the objective weights of experts based on evidence of similarity (DOWEBES) and basic probability assignment (BPA) proposed by [24]. In this case, weight determination for consistently ranking alternatives is in multiple criteria of decision analysis with TOPSIS method [30]. This problem is transformed into the compromise programming of seeking alternatives with a shorter distance to the ideal or a longer distance in the anti-ideal, despite the rankings based on the two distance measures possibly not being the same.

The development of weighting method also uses the approach on the effect of subjective, objective and combinative weightings in multiple criteria of decisionmaking. In this case, it requires weighting techniques combined with classical and new MCDM [12]. The classical weighting with hybrid models has been proposed to solve the problems of GDM in research. The example of those models are weights modified without involving the interests of stakeholders [31], the weighting made between participants from various stakeholders [29], hybrid models performed to determine the distance of the weight of each of the methods used in each of the criteria using AHP, fuzzy AHP, TOPSIS, Grey theory, fuzzy TOPSIS, Grey-TOPSIS [32] Grey model is used to improve the model of MCDM [32]-[34]. The combination of grey models with MCDM models uses SAW, TOPSIS and grey relational analysis (GRA). A hybrid group decision supports system using analytic hierarchy process, fuzzy set theory and neural network [35]. This study presents the application of a hybrid approach for group decision support for the supplier selection problem.

The new weighting, e.g. fuzzy simple additive weighting system (FSAWS) is performed by integrating fuzzy set theory (FST), factor rating system (FRS) and SAW [8], [25] and sensitivity analysis in SAW [36]. The modification weighting was done to improve the weighting algorithm in the previous research [29], [31], 
[37]. The weighting hybrid model is proposed to solve the objectivity of the problems, such as hybrid models required in the MCDM by combining AHP and Entropy in order to optimize the weight values of DM based on the model of objective programming [37]. Meanwhile, the fuzzy hybrid of MCDM approach for professional selection uses combination of Fuzzy ANP, Fuzzy TOPSIS, Fuzzy ELECTRE techniques [38]. Develop a triangular fuzzy power geometric (TFPG) operator and a triangular fuzzy weighted power geometric (TFWPG) operator for aggregating the DMs' preferences into the group preferences [39] a fuzzy multi-criteria group decision-making model based on Weighted Borda Scoring method [40], new MCDM in interval-valued hesitant fuzzy sets to selection problems [41], intervalvalued intuitionistic fuzzy continuous weighted entropy [42], the priority weights from incomplete hesitant fuzzy preference relations in group decision making [43].

The weighting process required the normalization process carried out in several studies group decision support system (GDSS) with MCDM [2]. In [8] also [44] to optimize the MCDM in providing weight values, the integration of subjectivity and objectivity of each parameter-criteria was required. The DM provides the value of decision matrix $D=\left\{d_{k j} \mid k, j=1,2, \ldots, \mathrm{n}\right\}$ [45], where elements $D$ by the following rules:

$$
d_{i j}>0 ; d_{j k}=\frac{1}{d_{k j}}, \text { and } d_{k k}=1 ; k, j=1,2, \ldots, \mathrm{n} .
$$

Where $d_{j k}$ shows the relative weights on attribute $C_{k}$ to attribute $C_{j}$. Weight total of normalized weights is equal to 1 . Equation (2) and (3) are the number $n$ of parameters from each set of weights defined as follows:

$$
\begin{gathered}
w=\left(w_{1}, w_{2}, \ldots w_{n}\right) \\
\sum w_{j}=1
\end{gathered}
$$

Based on the weight values of each parameter from a decision matrix $\boldsymbol{x}$ size $m \times n$, the contents of the elements are $x_{i j}$, that present the rating of an alternative $A_{i}=(i=1,2, \ldots, m)$ against the criteria $c_{j}=(j=$ $1,2, \ldots, n)$. The decision matrix $\boldsymbol{x}$ is defined as follows:

$$
x=\left[\begin{array}{cccc}
x_{11} & x_{12} & \cdots & x_{1 n} \\
x_{21} & x_{22} & \cdots & x_{2 n} \\
\vdots & \vdots & & \vdots \\
x_{m 1} & x_{m 2} & \cdots & x_{m n}
\end{array}\right]
$$

Equation (1) - (4) showing each parameter has a weight value based on the normalization process to obtain the score of weights used in the rankings. The stage of weighting is the basis for subsequent weighting process. The weights from each decision shows the relative interest from each of the parameters and criteria; the value of weights are assigned based on the interest level of DM [2], [10], [15], [21]. Another weighting process is a model of social networks (SN) [46], SN for decision support [47] where the weighting is based on the interests of the actors that have linkage relationships from each DM to DM [48].

Model SN applied by [46] to relate the interests of all stakeholders such as the relationship is based on institutional, knowledge, friendship, status and more. The next model is needed to integrate decision support and SN [49], i.e. adopting social networks for decision support within an organization [50].

\section{PROPOSED METHOD}

In this research, we propose a method to improve the results of weight update performed by decision maker $(\mathrm{DM})$ in the weighting parameter subjectively or objectively; it produces the weight which has combined the interests of each DM. Such as an example of equation (5), to get the result of weight update parameter $\left(P_{i}\right)$ which has similar relationship of parameters from each DM.

$$
W_{j}=\sum_{J} W_{D M i} * W_{P i}(D M), i=1,2, \ldots, \mathrm{n}
$$

$$
\begin{array}{ll}
\text { where } & \\
W_{j} & : \text { the weight value of similar } P_{i} \text { of each DM } \\
W_{D M i} & : \text { weights of DM that use } P_{i} \\
W_{P i} & : \text { the parameter weight of } P_{i} \text { for each DM } \\
i & : \text { the number of DM and parameters used }
\end{array}
$$

The stage in equation (5) uses the weight update of parameters to produce the alternative ranking of each DM. The weight values $\left(W_{j}\right)$ are the summation result process of weighting from $i$ parameter $\left(P_{i}\right)$ based on the parameters selection carried out by DM. The weight of $\mathrm{DM}\left(W_{D M i}\right)$ is the weight of each DM that uses $P_{i}$, while each weighting parameter $\left(W_{P i}\right)$ used by DM performed to summation the weighting until $W_{j}$ of each $P_{i}$ in DM. The index $(i)$ is the number of DM and parameter used in weighting process. Subsequently, the equation (6) is used to produce the final weight for the rankings used that is defined as follows:

$$
W_{j}^{i}=W_{D M i} *\left(1+W_{j}\right), i=1,2, \ldots, \mathrm{n}
$$

where $W_{j}^{i}$ is the result of the process to obtain the final weights used in the rankings in a group decision similar parameter in each DM. Each weighting process also requires normalization of weight, so that the weight value of 1 is produced from all DMs who use these parameters. This method describes how the algorithm updates the parameter weights in group decision-making based on the similar parameters. An overview of the weighting update method of parameters is proposed which produce weight to accommodate the interests of each stakeholder in decision-making as shown in Fig. 1.

Based on Fig. 1 there are several stages of the process to perform the weight update of parameters to be used in the subsequent ranking method. The algorithms of these stages are described as follows: 


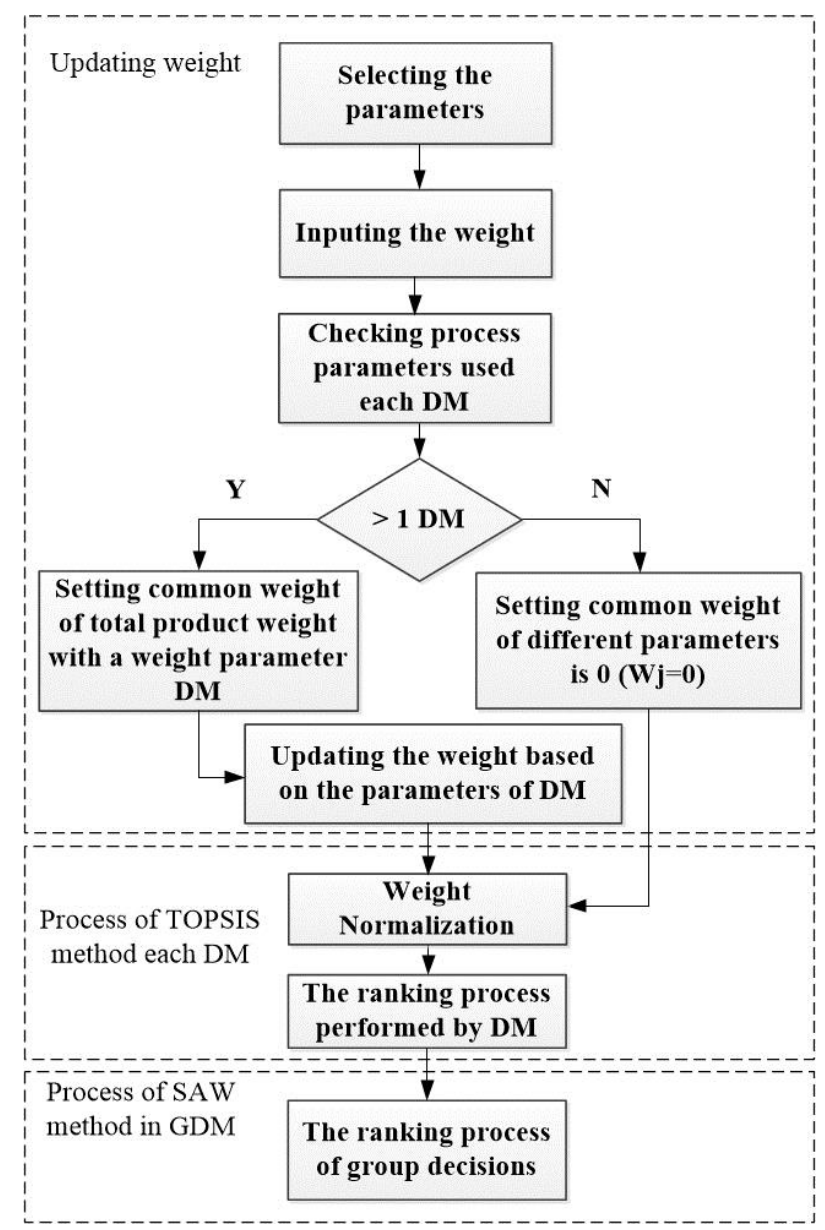

Fig.1. The proposed method for weight updating of parameter

Step 1. Each DM selects the parameters according to their interest.

Step 2. The weighting parameter is used to produce the initial weight value. This step uses MCDM method to get the initial weight.

Step 3. The initial weights value $\left(W_{P i}\right)$ of each parameter is used by DM, then the parameters of each $\mathrm{DM}_{i}$ relationship are checked.

Step 4. Check DM who uses the parameter $P_{i}$. If the parameter is similar (Y) to other DMs, compute the average value of the weights $\left(\mathrm{W}_{\mathrm{j}}\right)$. If the parameters are not similar $(\mathrm{T})$, the ranking process by each DM that is appropriate with the initial weight are performed.

Step 5. The update parameter of weight is implemented based on the similar parameters $\left(W_{P i}\right)$ from each DM.

Step 6. The result of $W_{j}$ that use $W_{P i}$ from each DM is implemented by equation (6) to obtain $W_{j}^{i}$.

Step 7. The value of weights used for the ranking process consists of the similar parameters and not similar from all DM from normalized weight $\left(W_{n}\right)$.

Step 8. All DMs applied in the ranking process by TOPSIS method use update weights to obtain the decision alternatives.
TOPSIS method consists of several stages: normalization of the decision matrix, normalization of weight, positive ideal solutions (PIS), and the negative ideal solutions (NIS) and specify the preferences for each alternative [3]. This method requires the alternative $\left(A_{i}\right)$ on each criterion $\left(C_{j}\right)$ that has been normalized [3], [4], [51] which is based on the concept that the best alternative have the lowest distance from the positive ideal solutions (PIS) and the largest distance from the negative ideal solutions (NIS) [52]. PIS presents the best solutions that maximize the attributes and minimize the attribute cost; otherwise, NIS presents the negative solutions that minimize the attributes and maximize the cost attribute [53]. The stages of normalization are performed by equation (7).

$$
r_{i j}=\frac{x_{i j}}{\sqrt{\sum_{i=1}^{m} x_{i j}^{2}}} ; \text { if } \mathrm{i}=1,2, \ldots, \mathrm{m}, \text { and } \mathrm{j}=1,2, \ldots, \mathrm{n} .
$$

Each positive ideal solutions (PIS) $w^{+}$and negative ideal solution (NIS) $w^{-}$can be determined by the normalized rate $\left(\mathrm{y}_{\mathrm{ij}}\right)$ using equation in (8), (9) and (10).

$$
\begin{aligned}
& \left(\mathrm{y}_{\mathrm{ij}}\right)=\mathrm{w}_{\mathrm{i}} \mathrm{r}_{\mathrm{ij}} ; \text { if } \mathrm{i}=1,2, \ldots, \mathrm{m} \text {, and } \mathrm{j}=1,2, \ldots, \mathrm{n} \\
& w^{+(\mathrm{PIS})}=\left(\mathrm{y}_{1}^{+}, \mathrm{y}_{2}^{+}, \ldots, \mathrm{y}_{\mathrm{n}}^{+}\right) \\
& \left\{\left(\operatorname{Max} v_{i j} \mid j \in J\right),\left(\operatorname{Min} v_{i j} \mid j \in J^{-}\right)\right\} \\
& w^{-(\mathrm{NIS})}=\left(\mathrm{y}_{1}^{-}, \mathrm{y}_{2}^{-}, \ldots, \mathrm{y}_{\mathrm{n}}^{-}\right) \\
& \left\{\left(\operatorname{Min}_{i j} \mid j \in J\right),\left(\operatorname{Max} v_{i j} \mid j \in J^{-}\right)\right\}
\end{aligned}
$$

After that, $y_{1}^{+}$is the max value ${ }_{1} y_{i j}$ to review the benefits attribute and $\min _{1} y_{i j}$ to review the cost attribute. And $y_{1}^{-}$is the min value of $\min _{1} y_{i j}$ to review the benefits attribute and of $\max _{1} y_{i j}$ to review the cost attribute. For a review, alternative distance of $A_{i}$ with positive ideal solutions (PIS) is calculated using equation (11).

$$
S_{-}^{+}=\sqrt{\sum_{j=1}^{n}\left(y_{i}^{+}-y_{i j}^{+}\right)^{2}} \quad ; i=1,2, \ldots, m .
$$

Thus, the distance between the negative ideal solutions (NIS) alternative $\left(A_{i}\right)$ is calculated using equation (12).

$$
S_{+}^{-}=\sqrt{\sum_{j=1}^{n}\left(y_{i}^{-}-y_{i j}^{-}\right)^{2}} \quad ; \quad i=1,2, \ldots, m .
$$

The preference value for each alternative $\left(A_{i}\right)$ is calculated using equation (13).

$$
V_{i}=\frac{s_{i}^{-}}{s_{i}^{-}+s_{i}^{+}} ; i=1,2, \ldots, m
$$

Step 9. The process of group decision-making is performed based on the decision result of each DM. This process requires normalization of the matrix (14) to a certain scale that can be compared with all the ratings of existing alternatives with the following equation: 


$$
r_{i j}=\left\{\begin{array}{c}
x_{i j} / x_{j}^{+}, j \in \Omega \max \\
x_{j}^{-} / x_{i j}, j \in \Omega \min
\end{array}\right.
$$

where $r_{i j}$ is the normalized value of the $i$ th alternative for the $j$ th criterion, $x_{j}^{+}$is the maximum number of $x_{i j}$ in the column of $j$ for benefit criterion, $x_{j}^{-}$is the minimum number of $x_{i j}$ in the column of $j$ for cost criterion, and $\Omega$ $\max$ and $\Omega \min$ are sets of benefit and cost criteria, respectively [34].

Furthermore, equation (15) is applied using attributes benefit to obtain group decision-making from the preference value for each alternative $\left(V_{i}\right)$ as follows:

$$
V_{i}=\sum_{j=1}^{n} w_{j} r_{i j}
$$

where $V_{i}$ is the ranking score of the $i$ th alternative, $w_{j}$ is the weight of the jth criterion, and $r_{i j}$ is the normalized performance of the ith alternative with respect to the $j$ th criterion. In the simple adaptive weighting (SAW) method, the ranking score $V_{i}$ represents the comprehensive performance of the $i$ th alternative, and the alternative with the highest value of $S_{i}$ is the highest ranked.

This weight update algorithm of parameter aims to improve the value of the initial weights filled by each DM. Subsequently, the weight is merged based on the interests of each DM from the similar parameter. This method also aims to increase the weight values of the parameters used by each DM based on the combined weight of each DM. Furthermore, the update weights are used to determine the ranking by TOPSIS method. This method produces a preference value for the alternative of decision each DM. The preferences values of the DM decision are used in the SAW method as input to obtain a group decision.

\section{RESULT AND DISCUSSION}

Based on Fig. 1, equation (5) and (6), we illustrate the relationship of parameters from each decision maker (DM). The architecture relationship of similar parameter aims to show the relationship of the parameters that used by each DM to updates the weighting. This architecture is depicted in Fig. 2. In this paper, we use 6 parameters, 3 groups of DM and 4 alternatives to solve this problem. Parameter 1 (P1) up to parameter 6 (P6) are used to alternative of each DM. In our opinion, the previous weighting method does not accommodate the interests of knowledge that is appropriate with the similar parameters used by DM in solving group decision-making.

Subsequently, we have to improve the weighting method by updating the initial weight to the final weight based on the similar parameters according to the parameters chosen by the DM.

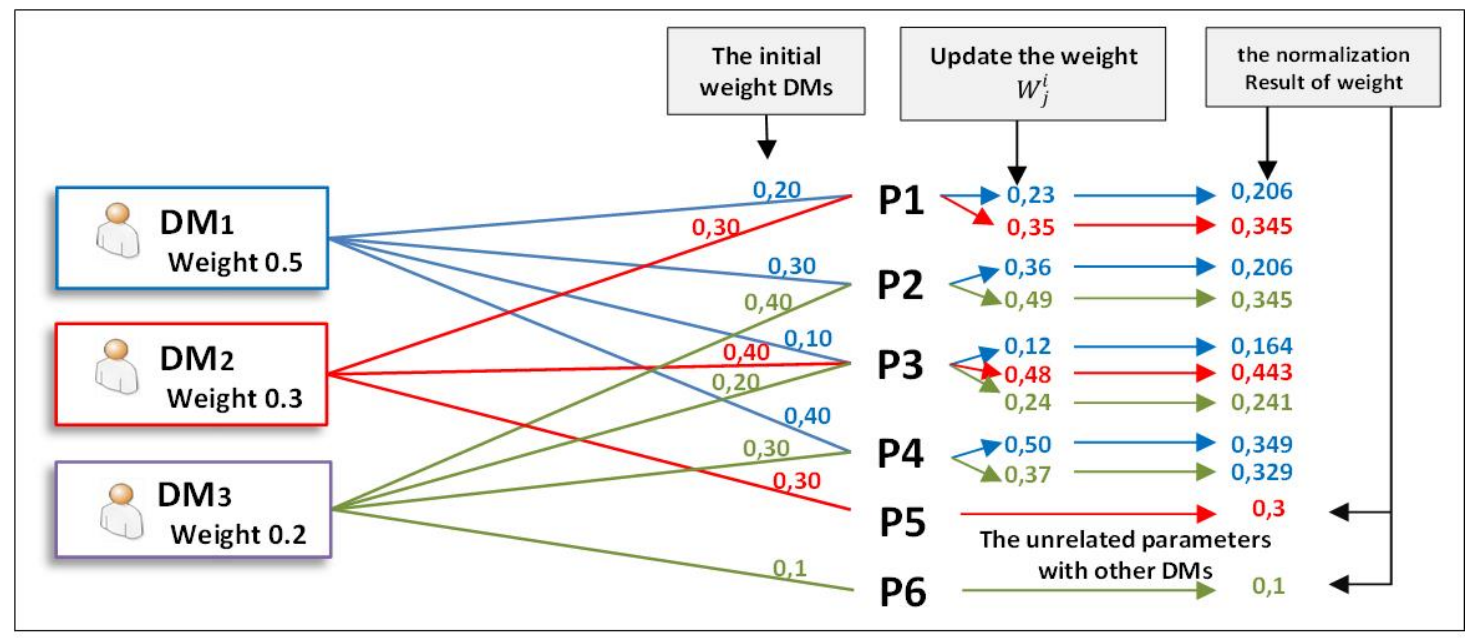

Fig.2. The architecture relation similarity of parameter for weight update

Fig. 2 shows that P1 is a parameter used by DM1 and DM2 with different weights. P2 and P4 are used by DM1 to DM3, P3 used by DM1, DM2 and DM3, while P5 and P6 are only used by DM2 and DM3, respectively. In order to accomplish the problem according to Fig. 2, the testing was implemented using TOPSIS to know the results of alternative decisions using four alternative groups and 6 parameters by scoring from 1 to 5 . The alternative data and parameters used in this paper are shown in Table 1.
Table 1. The parameter and alternatives

\begin{tabular}{|c|c|c|c|c|c|c|}
\hline Alternatives & P1 & P2 & P3 & P4 & P5 & P6 \\
\hline A1 & 3 & 4 & 5 & 2 & 3 & 2 \\
\hline A2 & 2 & 2 & 2 & 1 & 5 & 4 \\
\hline A3 & 4 & 3 & 4 & 5 & 2 & 4 \\
\hline A4 & 3 & 4 & 2 & 5 & 2 & 3 \\
\hline
\end{tabular}


Based on Table 1, data ranking obtained using a weight update method that has accommodated the interests of each DM. The weights used are the weight updates obtained from the direct weight previously.

In equation (1), it is known that each DM has the initial weight namely $W_{P i}$ which has similarities to each parameter. Then, $W_{P i}$ is used by each DM to produce the weight updates based on the number of $P_{i}$. Furthermore, $W_{j}$ and $W_{j}^{i}$ are carried out using equation (5) and equation (6), respectively according to $D M_{i}$ on each $P_{i}$. While for those are not similar parameters, these processes are not required.

In this paper, we set the weight value of DM1, DM2 and DM3 at 0.5, 0.3, and 0.2, respectively for each DM. The results of weight update for each parameter by DM for $\left(W_{P i}\right)$ and $\left(W_{j}^{i}\right)$, to produce $\left(W_{n}\right)$, are summarized in Table 2, Table 3 and Table 4.

Table 2. The weight update of parameters DM1

\begin{tabular}{|c|c|c|c|c|}
\hline $\begin{array}{c}\text { The weight of } \\
\text { DM1 }\end{array}$ & $\begin{array}{c}\text { Selected } \\
\text { parameter }\left(P_{i}\right)\end{array}$ & $\begin{array}{c}\text { Initial } \\
\text { weight }\left(W_{P i}\right)\end{array}$ & $\begin{array}{c}\text { Updated weight } \\
\left(W_{j}^{i}\right)\end{array}$ & $\begin{array}{c}\text { Normalized } \\
\text { weight }\left(W_{n}\right)\end{array}$ \\
\hline \multirow{5}{*}{0.5} & $\mathrm{P} 1$ & 0.20 & 0.238 & 0.193 \\
\cline { 2 - 5 } & $\mathrm{P} 2$ & 0.30 & 0.369 & 0.300 \\
\cline { 2 - 5 } & $\mathrm{P} 3$ & 0.10 & 0.121 & 0.098 \\
\cline { 2 - 5 } & $\mathrm{P} 4$ & 0.40 & 0.504 & 0.409 \\
\cline { 2 - 5 } & & 1 & 1.232 & 1 \\
\hline
\end{tabular}

In order to evaluate the effectiveness of the algorithm of weight updates, the ranking method is needed. Based on the weight updates on Table 2, the normalized attribute value is then used to form a normalized matrix $(R)$ and multiplying the weight $\left(W_{n}\right)$ with the value from each attribute to obtain the value of normalized weight. The result of $R$ values is shown as follows:

$$
R=\left[\begin{array}{llll}
0.487 & 0.596 & 0.598 & 0.270 \\
0.324 & 0.298 & 0.598 & 0.135 \\
0.649 & 0.447 & 0.478 & 0.674 \\
0.487 & 0.596 & 0.239 & 0.674
\end{array}\right]
$$

Furthermore, $Y$ value consists of the value of the positive ideal solution (PIS) and negative ideal solution (NIS) for the distance of weight. The $Y$ value is shown as follows:

$$
Y=\left[\begin{array}{llll}
0.094 & 0.179 & 0.059 & 0.110 \\
0.063 & 0.089 & 0.059 & 0.055 \\
0.125 & 0.134 & 0.047 & 0.276 \\
0.094 & 0.179 & 0.023 & 0.276
\end{array}\right]
$$

We applied TOPSIS method to determine the distance of each weight from the parameter and alternatives. Based on Table 2, the result of $\mathrm{PIS}^{+}$and NIS ${ }^{-}$of DM1 are as follow:

$$
\mathrm{PIS}^{+}=0.125 ; 0.179 ; 0.059 ; 0.276
$$$$
\mathrm{NIS}^{-}=0.063 ; 0.089 ; 0.023 ; 0.055
$$

$\mathrm{PIS}^{+}$and NIS ${ }^{-}$produce the alternative of distance $A i$ with a solution of positive ideal $\left(\mathrm{S}_{i}^{+}\right)$and ideal negative $\left(\mathrm{S}_{\mathrm{i}}^{-}\right)$. The results of $\mathrm{S}_{\mathrm{i}}^{+}$and $\mathrm{S}_{\mathrm{i}}^{-}$are as follows:

$\mathrm{S}_{1}^{+}=0.168 ; \mathrm{S}_{2}^{+}=0.246 ; \mathrm{S}_{3}^{+}=0.046 ; \mathrm{S}_{4}^{+}=0.047$

$\mathrm{S}_{1}^{-}=0.115 ; \mathrm{S}_{2}^{-}=0.035 ; \mathrm{S}_{3}^{-}=0.235 ; \mathrm{S}_{4}^{-}=0.240$

The next stage, the calculation process of DM2 was performed such as DM1. We chose three parameters namely P1, P3, and P5 with the weights of parameters and the weight of DM reported in Table 3.

Table 3. The weight update of parameters DM2

\begin{tabular}{|c|c|c|c|c|}
\hline $\begin{array}{c}\text { The weight of } \\
\text { DM2 }\end{array}$ & $\begin{array}{c}\text { Selected } \\
\text { parameter }\left(P_{i}\right)\end{array}$ & $\begin{array}{c}\text { Initial } \\
\text { weight }\left(W_{P i}\right)\end{array}$ & $\begin{array}{c}\text { Updated weight } \\
\left(W_{j}^{i}\right)\end{array}$ & $\begin{array}{c}\text { Normalized } \\
\text { Weight }\left(W_{n}\right)\end{array}$ \\
\hline \multirow{4}{*}{0.3} & P1 & 0.30 & 0.357 & 0.313 \\
\cline { 2 - 5 } & P3 & 0.40 & 0.484 & 0.424 \\
\cline { 2 - 5 } & P5 & 0.30 & 0.327 & 0.263 \\
\cline { 2 - 5 } & \multicolumn{3}{|r}{} \\
\hline
\end{tabular}

The result of $R$ values and $Y$ based on the weight of DM2 are as follows:

$$
R=\left[\begin{array}{lll}
0.487 & 0.598 & 0.463 \\
0.324 & 0.598 & 0.772 \\
0.649 & 0.478 & 0.309 \\
0.487 & 0.239 & 0.309
\end{array}\right]
$$

$$
Y=\left[\begin{array}{lll}
0.152 & 0.254 & 0.122 \\
0.102 & 0.254 & 0.203 \\
0.203 & 0.203 & 0.081 \\
0.152 & 0.101 & 0.081
\end{array}\right]
$$

Accordingly, the distance from the PIS and NIS of DM2 based on Table 3 of each of the weights are as follows: 
$\mathrm{PIS}^{+}=0.203 ; 0.254 ; 0.203$

$\mathrm{NIS}^{-}=0.102 ; 0.101 ; 0.081$

$\mathrm{S}_{1}^{+}=0.096 ; \mathrm{S}_{2}^{+}=0.102 ; \mathrm{S}_{3}^{+}=0.132 ; \mathrm{S}_{4}^{+}=0.201$

$\mathrm{S}_{1}^{-}=0.165 ; \mathrm{S}_{2}^{-}=0.195 ; \mathrm{S}_{3}^{-}=0.143 ; \mathrm{S}_{4}^{-}=0.051$
We used four parameters for DM3, namely P2, P3, P4 and P6 with different weights. There are similarity of parameters that are selected by DM3 with DM1 and DM2. The details parameters for DM3 reported in Table 4.

Table 4. The weight update of parameters DM3

\begin{tabular}{|c|c|c|c|c|}
\hline $\begin{array}{c}\text { The weight of } \\
\text { DM3 }\end{array}$ & $\begin{array}{c}\text { Selected } \\
\text { parameter }\left(P_{i}\right)\end{array}$ & $\begin{array}{c}\text { Initial } \\
\text { weight }\left(W_{P i}\right)\end{array}$ & $\begin{array}{c}\text { Updated weight } \\
\left(W_{j}^{i}\right)\end{array}$ & $\begin{array}{c}\text { Normalized } \\
\text { weight }\left(W_{n}\right)\end{array}$ \\
\hline \multirow{5}{*}{0.2} & $\mathrm{P} 2$ & 0.40 & 0.492 & 0.406 \\
\cline { 2 - 5 } & $\mathrm{P} 3$ & 0.20 & 0.242 & 0.200 \\
\cline { 2 - 5 } & $\mathrm{P} 4$ & 0.30 & 0.378 & 0.312 \\
\cline { 2 - 5 } & $\mathrm{P} 6$ & 0.10 & 0.102 & 0.083 \\
\hline
\end{tabular}

The value of $R$ and $Y$ based on the weight of DM3 with four parameters are as follows:

$$
\begin{array}{r}
R=\left[\begin{array}{llll}
0.596 & 0.598 & 0.270 & 0.298 \\
0.298 & 0.598 & 0.135 & 0.596 \\
0.447 & 0.478 & 0.674 & 0.596 \\
0.596 & 0.239 & 0.674 & 0.447
\end{array}\right] \\
Y=\left[\begin{array}{llll}
0.242 & 0.119 & 0.084 & 0.025 \\
0.121 & 0.119 & 0.042 & 0.049 \\
0.182 & 0.095 & 0.210 & 0.049 \\
0.242 & 0.048 & 0.210 & 0.037
\end{array}\right]
\end{array}
$$

The distance from the PIS and NIS for DM3 based on Table 4 of each of the weights are as follows:
$\mathrm{PIS}^{+}=0.242 ; 0.119 ; 0.210 ; 0.049$

$\mathrm{NIS}^{-}=0.121 ; 0.048 ; 0.042 ; 0.025$

$\mathrm{S}_{1}^{+}=0.129 ; \mathrm{S}_{2}^{+}=0.207 ; \mathrm{S}_{3}^{+}=0.065 ; \mathrm{S}_{4}^{+}=0.073$

$\mathrm{S}_{1}^{-}=0.147 ; \mathrm{S}_{2}^{-}=0.076 ; \mathrm{S}_{3}^{-}=0.187 ; \mathrm{S}_{4}^{-}=0.208$

Based on our weight update method, we used the value of preference according to the alternative of decisions from $\mathrm{DM} 1=\mathrm{A} 4, \mathrm{DM} 2$ and $\mathrm{DM} 3=\mathrm{A} 2=\mathrm{A} 3$. The preference value that is larger than the alternative of DM becomes a recommendation for each DM.

The preference value of each DM produces alternative decisions on a ranking that can be shown in Table 5.

Table 5. The results of the ranking of each DM with the proposed method and initial weight

\begin{tabular}{|c|c|c|c|c|c|c|}
\hline \multirow{2}{*}{ Alternatives } & \multicolumn{3}{|c|}{ Initial weight } & \multicolumn{3}{c|}{ Proposed method } \\
\cline { 2 - 7 } & $\mathrm{DM}_{1}$ & $\mathrm{DM}_{2}$ & $\mathrm{DM}_{3}$ & $\mathrm{DM}_{1}$ & $\mathrm{DM}_{2}$ & $\mathrm{DM}_{3}$ \\
\hline A1 & 0.411 & 0.602 & 0.633 & 0.406 & 0.633 & 0.533 \\
\hline A2 & 0.129 & $\mathbf{0 . 6 7 2}$ & $\mathbf{0 . 6 6 5}$ & 0.125 & $\mathbf{0 . 6 6 5}$ & 0.268 \\
\hline A3 & $\mathbf{0 . 8 3 3}$ & 0.482 & 0.521 & 0.836 & 0.521 & $\mathbf{0 . 7 4 2}$ \\
\hline A4 & 0.830 & 0.191 & 0.201 & $\mathbf{0 . 8 3 7}$ & 0.201 & 0.741 \\
\hline
\end{tabular}

Table 5 shows that the alternatives decision of the proposed method for the first rank of DM1, DM2 and DM3 are A3 (0.837), A2 (0.665) and A3 (0.742), respectively. It shows that each DM has the decisions with different preferences value. Meanwhile, the first rank produced by the DM1, DM2 and DM3 are A3 (0833), A2 (0672) and A2 (0.665), respectively. In this stage, the ranking process of each DM is applied; therefore, the decision of the group is obtained. The alternative analysis results of each DM are illustrated in Fig. 3.

Group analysis is applied based on the rank result of each DM reported in Table 5. The output of GDM shows the preference values from all DM used in decisionmaking. Based on Table 6, the rank results of the alternatives between the initial weight and the proposed method have the same order, namely A3, A4, A1, and A2. The preference values of GDM that uses initial weight for A3 (0.915), A4 (0.782), A1 (0.661), and A2 (0.453), respectively.

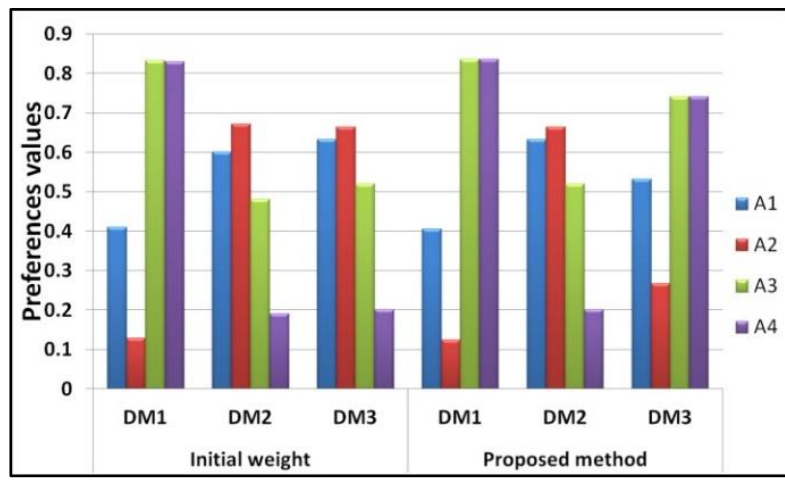

Fig.3. The comparison of result that obtained by the initial weight and the proposed method

While the result of preference value by the proposed method for A3 (0.938), A4 (0.792), A1 (0.676), and A2 (0.447), respectively. The preference value obtained by the proposed method is larger than the initial weight. It indicates that the rank results of the proposed method are 
more convincing than the use of initial weight. The results of GDM obtain A3 as recommendations with a preference values is 0.938 as the first rank (R1) as shown in Table 6.

Table 6. The decision result of the group decision-making (GDM) with Initial weight and proposed method

\begin{tabular}{|c|c|c|c|c|c|c|c|c|c|c|}
\hline \multirow[b]{2}{*}{ Alternatives } & \multicolumn{5}{|c|}{ Initial weight } & \multicolumn{5}{|c|}{ Proposed method } \\
\hline & DM1 & DM2 & DM3 & $\begin{array}{c}\text { Preferences } \\
\text { group }\end{array}$ & Ranking & DM1 & DM2 & DM3 & $\begin{array}{l}\text { Preferences } \\
\text { group }\end{array}$ & Ranking \\
\hline A1 & 0.247 & 0.269 & 0.145 & 0.661 & 3 & 0.243 & 0.289 & 0.144 & 0.676 & 3 \\
\hline A2 & 0.077 & 0.300 & 0.075 & 0.453 & 4 & 0.075 & 0.300 & 0.072 & 0.447 & 4 \\
\hline A3 & 0.500 & 0.215 & 0.200 & 0.915 & 1 & 0.500 & 0.238 & 0.200 & 0.938 & 1 \\
\hline A4 & 0.498 & 0.085 & 0.199 & 0.782 & 2 & 0.500 & 0.092 & 0.200 & 0.792 & 2 \\
\hline
\end{tabular}

The results of the analysis of group in Table 6 shows A3 has different values in DM2 to generate the final of preferences value. The last stage is the calculation of the ranking value of group decision-making (GDM) based on the rank result of each DM using the initial weight and the weight update in the proposed method. The comparison of result obtained by the initial weight and the proposed method is illustrated in Fig. 4. It shows that the preference value obtained by proposed method is larger than the initial weight.

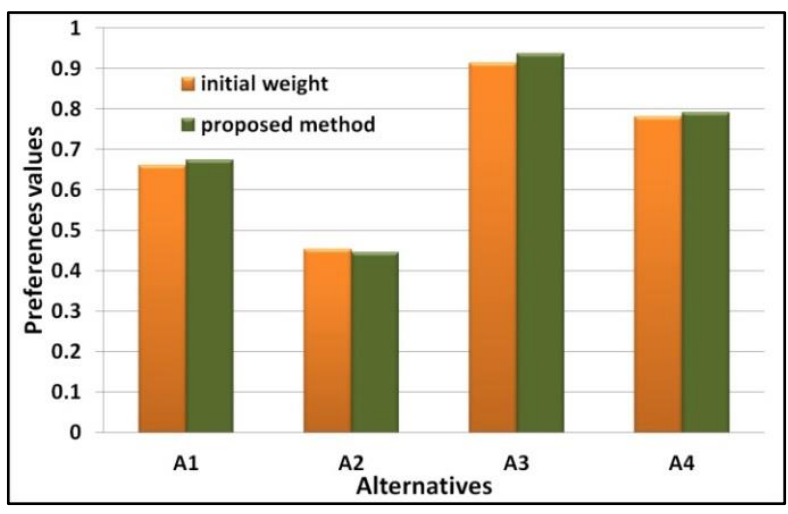

Fig.4. The results of ranking in group decision-making (GDM)

The results of the final analysis (see Fig. 4) indicate that the comparison of the proposed method reveals higher scores than using the initial weight. Other advantage using weight update method is that it considers all interests in the group such that the group decision making process will reflect fairness all DMs having more common criteria.

\section{CONCLUSION}

In this paper, we propose the weight update method based on the similar parameters used by DM. We prove that the result of our proposed method with weight update of the parameter is used by all DMs to make alternative decisions. The initial weight has to be updated because there are similar parameters on each DM. While the weight update is not required against the DMs who do not have similar parameters. The weight update $\left(W_{j}^{i}\right)$ aims to overcome the different knowledge of each stakeholder in selecting parameters and determining the weight value of the different parameter. The experimental results of group decision in this paper obtain the alternative (A3) as the first rank with the preferences value of 0.938. Meanwhile, without the use of the weight update, it has a preference value of 0.915 , which is lower than the proposed method. This method is our contribution to accommodate the conflict of interest of DM in the selection of the parameters and weight to determine the GDM.

\section{FUTURE WORK}

For future work, we will develop the weighting hybrid models by implementing the method of multi-criteria decision-making (MCDM), social networks (SN) and stakeholders for GDM. It aims to reduce conflicts of interest in group decision from the process of selecting the parameter, parameter weighting, and weighting group. The weight of DM for the future work has also influenced the power and interest based on the model of stakeholders therefore, those may improve the previous model of group decision-making by giving DM weight value directly.

\section{REFERENCES}

[1] R. R. Yager, "Uncertainty modeling and decision support," Reliab. Eng. Syst. Saf., vol. 85, no. 1-3, pp. 341-354, Jul. 2004.

[2] C. Kahraman, "Fuzzy Multi-Criteria Decision Making," vol. 16, pp. 1-18, 2008.

[3] C. L. Hwang and K. Yoon, Multiple Attribute Decision Making: Methods and Applications. New York: SpringerVerlag, 1981.

[4] D. L. Olson, "Comparison of Weights in TOPSIS Models," Math. Comput. Model., vol. 40, pp. 721-727, 2004.

[5] T. L. Saaty and L. G. Vargas, "Comparison of eigenvalue, logarithmic least squares and least squares methods in estimating ratios," Math. Model., vol. 5, no. 5, pp. 309324, 1984.

[6] T. Saaty and I. Basak, "Group Decision Making Using The Analytic Hierarchy Process," Math. Comput. Model., vol. 17, no. 4-5, pp. 101-109, 1993.

[7] T. L. Saaty and M. Ozdemir, "Negative Priorities in the Analytic Hierarchy Process," Math. Comput. Model., vol. 37, no. 9-10, pp. 1063-1075, 2003.

[8] S.-Y. Chou, Y.-H. Chang, and C.-Y. Shen, "A fuzzy simple additive weighting system under group decisionmaking for facility location selection with objective/subjective attributes," Eur. J. Oper. Res., vol. 189, no. 1, pp. 132-145, Aug. 2008.

[9] L. Abdullah and A. Otheman, "A New Entropy Weight for Sub-Criteria in Interval Type-2 Fuzzy TOPSIS and Its Application,” Int. J. Intell. Syst. Appl. (IJISA), vol. 5, no. 
2, pp. 25-33, Jan. 2013.

[10] L. Garc, "Weighting Individual Opinions in Group Decision Making," in Modeling Decisions for Artificial Intelligence, 2007, pp. 92-103.

[11] R. R. Yager, "Multiple objective decision - making using fuzzy sets," Int. J. Man. Mach. Stud., vol. 9, no. 4, p. 1977 1977.

[12] M. Alemi-Ardakani, A. S. Milani, S. Yannacopoulos, and G. Shokouhi, "On the effect of subjective, objective and combinative weighting in multiple criteria decision making: A case study on impact optimization of composites," Expert Syst. Appl., vol. 46, pp. 426-438, Mar. 2016

[13] A. Davey and D. Olson, "Multiple Criteria Decision Making Models in Group Decision Support," Gr. Decis. Negot., vol. 7, pp. 55-75, 1998.

[14] G. DeSanctis and R. B. Gallupe, "A Foundation for the Study of Group Decision Support Systems," Manage. Sci., vol. 33, no. 5, pp. 589-609, May 1987.

[15] Z. Wang, "An Adjustment Method of Experts ' Weights in Group Decision," in International Conference on EProduct E-Service and E-Entertainment (ICEEE), 2010, pp. $1-5$.

[16] X. Delgado-Galván, J. Izquierdo, J. Benítez, and R. PérezGarcía, "Joint stakeholder decision-making on the management of the Silao-Romita aquifer using AHP," Environ. Model. Softw., vol. 51, pp. 310-322, Jan. 2014.

[17] A. Zerger, G. Warren, P. Hill, D. Robertson, A. Weidemann, and K. Lawton, "Multi-criteria assessment for linking regional conservation planning and farm-scale actions," Environ. Model. Softw., vol. 26, no. 1, pp. 103 110, Jan. 2011.

[18] M. D. Chavez, P. B. M. Berentsen, and A. G. J. M. O. Lansink, "Assessment of criteria and farming activities for tobacco diversification using the Analytical Hierarchical Process (AHP) technique," Agric. Syst., vol. 111, pp. 5362, 2012.

[19] B. Srdjevic and Z. Srdjevic, "Synthesis of individual best local priority vectors in AHP-group decision making," Appl. Soft Comput., vol. 13, no. 4, pp. 2045-2056, Apr. 2013.

[20] B. Liu, Y. Shen, Y. Chen, X. Chen, and Y. Wang, "A two-layer weight determination method for complex multi-attribute large-group decision-making experts in a linguistic environment," Inf. Fusion, vol. 23, pp. 156-165, May 2015.

[21] S. A. Hajkowicz, "Supporting multi-stakeholder environmental decisions.," J. Environ. Manage., vol. 88, no. 4, pp. 607-14, Sep. 2008.

[22] P. C. Campo, F. Bousquet, and T. R. Villanueva, "Modelling with stakeholders within a development project," Environ. Model. Softw., vol. 25, no. 11, pp. 1302-1321, Nov. 2010.

[23] H. Mianabadi, A. Afshar, and M. Zarghami, "Intelligent multi-stakeholder environmental management," Expert Syst. Appl., vol. 38, no. 1, pp. 862-866, Jan. 2011.

[24] W. Lu, C. Liang, and Y. Ding, "Experts Based on Evidence Similarity in Group Decision-making," in 4th International Conference on Wireless Communications, Networking and Mobile Computing, 2008, pp. 1-4.

[25] X. Zhai and R. Xu, "A Weighting Multicriteria Group Decision-Making Model in Fuzzy Environment," in 2010 Second WRI Global Congress on Intelligent Systems (GCIS), 2010, pp. 187-190.

[26] S. Sener, E. Sener, B. Nas, and R. Karagüzel, "Combining AHP with GIS for landfill site selection: a case study in the Lake Beyşehir catchment area (Konya, Turkey).,"
Waste Manag., vol. 30, no. 11, pp. 2037-46, Nov. 2010.

[27] H. Hamdani and S. Hartati, "Geographics Visualization for Decision Support System of Culinary Tourism Use Rule Of Thumb Methode," in Seminar Teknik Informatika, 2011, no. January.

[28] D. Liang, D. Liu, and A. Kobina, "Three-way group decisions with decision-theoretic rough sets," Inf. Sci. (Ny)., vol. 345, pp. 46-64, Jun. 2016.

[29] Y. Liu, Z.-P. Fan, and X. Zhang, "A method for large group decision-making based on evaluation information provided by participators from multiple groups," Inf. Fusion, vol. 29, pp. 132-141, May 2016.

[30] C. Kao, "Weight determination for consistently ranking alternatives in multiple criteria decision analysis," Appl. Math. Model., vol. 34, no. 7, pp. 1779-1787, Jul. 2010.

[31] K. H. Oh, H. K. Kang, J. C. Park, and H. Y. Youn, "WAGE: Weighting with AHP, Grey Numbers, and Entropy for Multiple-Criteria Group Decision Making Problem," 2013 IEEE 16th Int. Conf. Comput. Sci. Eng., pp. 360-367, Dec. 2013.

[32] B. Oztaysi, "A decision model for information technology selection using AHP integrated TOPSIS-Grey: The case of content management systems," Knowledge-Based Syst., vol. 70, pp. 44-54, Nov. 2014.

[33] Y. Ju, "A new method for multiple criteria group decision making with incomplete weight information under linguistic environment," Appl. Math. Model., vol. 38, no. 21-22, pp. 5256-5268, Nov. 2014.

[34] P. Wang, Z. Zhu, and Y. Wang, "A novel hybrid MCDM model combining the SAW, TOPSIS and GRA methods based on experimental design," Inf. Sci. (Ny)., vol. 345, pp. 27-45, Jun. 2016.

[35] A. K. Kar, "A hybrid group decision support system for supplier selection using analytic hierarchy process, fuzzy set theory and neural network," J. Comput. Sci., vol. 6, pp. 23-33, Jan. 2015.

[36] W. S. Goodridge, "Sensitivity Analysis Using Simple Additive Weighting Method," Int. J. Intell. Syst. Appl.(IJISA), vol. 8, no. 5, pp. 27-33, May. 2016.

[37] H. Hai-feng and S. Yi, "Adaptive Algorithm for Adjusting Weights in Multiple Attributes Group Decision Making," 2013 Sixth Int. Symp. Comput. Intell. Des., pp. 390-394, Oct. 2013.

[38] M. Kabak, S. Burmaoğlu, and Y. Kazançoğlu, "A fuzzy hybrid MCDM approach for professional selection," Expert Syst. Appl., vol. 39, no. 3, pp. 3516-3525, Feb. 2012.

[39] M. Dong, S. Li, and H. Zhang, "Approaches to group decision making with incomplete information based on power geometric operators and triangular fuzzy AHP," Expert Syst. Appl., vol. 42, no. 21, pp. 7846-7857, Nov. 2015.

[40] H. Fanghua and C. Guanchun, "A Fuzzy Multi-Criteria Group Decision-Making Model Based on Weighted Borda Scoring Method for Watershed Ecological Risk Management: a Case Study of Three Gorges Reservoir Area of China," Water Resour. Manag., vol. 24, no. 10, pp. 2139-2165, Dec. 2009.

[41] H. Gitinavard, S. M. Mousavi, and B. Vahdani, "A new multi-criteria weighting and ranking model for group decision-making analysis based on interval-valued hesitant fuzzy sets to selection problems," Neural Comput. Appl., vol. 27, pp. 1593-1605, Jun. 2016.

[42] F. Jin, L. Pei, H. Chen, and L. Zhou, "Knowledge-Based Systems Interval-valued intuitionistic fuzzy continuous weighted entropy and its application to multi-criteria fuzzy group decision making," Knowledge-Based Syst., 
vol. 59, pp. 132-141, 2014.

[43] Y. Xu, L. Chen, R. M. Rodríguez, F. Herrera, and H. Wang, "Deriving the priority weights from incomplete hesitant fuzzy preference relations in group decision making," Knowledge-Based Syst., vol. 99, pp. 71-78, May 2016.

[44] M. A. Abo-Sinna and T. H. M. Abou-El-Enien, "An interactive algorithm for large scale multiple objective programming problems with fuzzy parameters through TOPSIS approach," Appl. Math. Comput., vol. 177, no. 2, pp. 515-527, Jun. 2006.

[45] T. L. Saaty, "Rank from comparisons and from ratings in the analytic hierarchy/network processes I," vol. 168, pp. 557-570, 2006.

[46] J. A. Recio-García, L. Quijano, and B. Díaz-Agudo, "Including social factors in an argumentative model for Group Decision Support Systems," Decis. Support Syst., vol. 56, pp. 48-55, Dec. 2013.

[47] I. Ting, "Analyzing and Mining Social Networks for Decision Support," J. Univers. Comput. Sci., vol. 22, no. 3, pp. 298-301, 2016.

[48] B. Zhu, S. Watts, and H. Chen, "Visualizing social network concepts," Decis. Support Syst., vol. 49, no. 2, pp. 151-161, May 2010.

[49] F. Antunes and J. P. Costa, "Integrating Decision Support and Social Networks," Adv. Human-Computer Interact., vol. 2012, pp. 1-10, 2012.

[50] F. Antunes and J. P. Costa, "Decision Support Social Network," in 2011 6th Iberian Conference on Information Systems and Technologies (CISTI), 2011.

[51] G. R. Jahanshahloo, F. H. Lotfi, and M. Izadikhah, "An algorithmic method to extend TOPSIS for decisionmaking problems with interval data," Appl. Math. Comput., vol. 175, no. 2, pp. 1375-1384, Apr. 2006.

[52] A. Sepehr and C. Zucca, "Ranking desertification indicators using TOPSIS algorithm," Nat. Hazards, vol. 62, no. 3, pp. 1137-1153, Mar. 2012.

[53] X. Zhu, J. Li, D. Wu, H. Wang, and C. Liang, "Balancing accuracy, complexity and interpretability in consumer credit decision making: A C-TOPSIS classification approach," Knowledge-Based Syst., vol. 52, pp. 258-267, Nov. 2013.

\section{Authors' Profiles}

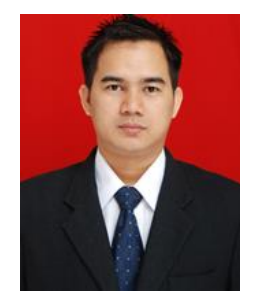

Hamdani Hamdani is a lecturer and a researchers at Department of Computer Science in Universitas Mulawarman, Indonesia. He obtained his bachelor degree of Informatics in Universitas Ahmad Dahlan, Indonesia (2002). He obtained his Master of Computer Science in Universitas Gadjah Mada, Indonesia (2009) and candidate his Ph.D program in Computer Science at Department of Computer Science \& Electronics in Universitas Gadjah Mada, Yogyakarta, Indonesia. His research interests include decision support systems (DSS), group decision support systems (GDSS), social networks analysis and web engineering.

E-mail: hamdani@fkti.unmul.ac.id / danifn@mail.ugm.ac.id.

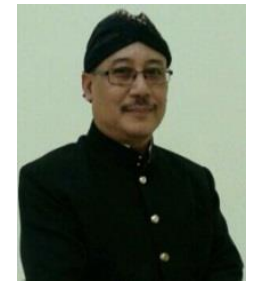

Retantyo Wardoyo is a lecturer and a researchers at Department of Computer Science and Electronics in Universitas Gadjah Mada, Indonesia. He obtained his bachelor degree from Mathematics in Universitas Gadjah Mada, Indonesia (1982). He obtained his master degree of Computer Science in University of Manchester, UK (M.Sc., 1990) and his doctoral degree from Computation in University of Manchester Institute of Science and Technology, UK (Ph.D., 1996). His research interests include Intelligent Systems, Knowledge Based Systems, Reasoning Systems, Expert Systems, Fuzzy Systems, Vision Systems, Decision Support Systems (DSS), Group DSS \& Clinical DSS, Medical Computing \& Computational Intelligence.

E-mail : rw@ugm.ac.id.

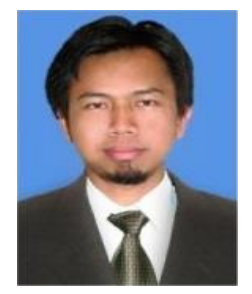

Khabib Mustofa is a lecturer and a researchers at Department of Computer Science and Electronics in Universitas Gadjah Mada, Indonesia. He obtained his bachelor degree of Computer Science in Universitas Gadjah Mada, Indonesia (1997) and Master of Computer Science from Universitas Gadjah Mada (2001) and received Ph.D. from Vienna University of Technology, Austria (2007). His research interests include database system, semantic web, web engineering and information management.

E-mail: khabib@ugm.ac.id.

How to cite this paper: Hamdani Hamdani, Retantyo Wardoyo, Khabib Mustofa, "A Method of Weight Update in Group Decision-Making to Accommodate the Interests of All the Decision Makers", International Journal of Intelligent Systems and Applications(IJISA), Vol.9, No.8, pp.1-10, 2017. DOI: 10.5815/ijisa.2017.08.01 